\title{
HTLV-1 infection modulates the immune response in HIV-HCV coinfected patients and may increase spontaneous HCV clearance
}

\author{
Fabianna Bahia', Marcos H Abrahão ${ }^{1}$, Eduardo M Netto ${ }^{1}$, Patricia Bozza², Carlos Brites ${ }^{1 *}$ \\ From 16th International Conference on Human Retroviruses: HTLV and Related Viruses \\ Montreal, Canada. 26-30 June 2013
}

\section{Background}

HTLV-1 often infect HIV-HCV coinfected patients. The immunological consequences of triple infection are still unclear. Objective: to compare the plasma levels of 25 different cytokines in patients infected by HIV and $\mathrm{HCV}$, according to their serological status to HTLV-1 infection.

\section{Methods}

We used the LUMINEX 100/200 analyzer to compare the plasma levels of 25 different cytokines for patients coinfected by HCV and HIV $(\mathrm{N}=15)$, or by HTLV-1, $\mathrm{HCV}$ and $\mathrm{HIV}(\mathrm{N}=18,3$ of them spontaneously cleared $\mathrm{HCV})$.

\section{Results}

We detected a significant increase in median plasma levels of 6 different cytokines (Table 1) for patients coinfected by HTLV-1.Only the 3 patients with HCV spontaneous clearance showed detectable levels of IL-15 $(\mathrm{p}=0.06)$. Levels of remaining 18 cytokines were similar for all groups.

\section{Conclusions}

Infection by HTLV-1, in HIV-HCV coinfected patients, seems to induce a greater release of pro-inflamatory cytokines. This can be associated with a higher rate of $\mathrm{HCV}$ spontaneous clearance.
Table 1

\begin{tabular}{ccccc}
\hline \multirow{4}{*}{ Cytokines } & \multicolumn{3}{c}{$\begin{array}{c}\text { Median Plasma levels of } \\
\text { cytokines, according to type of infection }\end{array}$} & \\
\cline { 2 - 4 } & $\begin{array}{c}\text { HIV+ HTLV } \\
\text { (spontaneous } \\
\text { clearance of HCV) }\end{array}$ & $\begin{array}{c}\text { HIV+ HTLV } \\
\text { +HCV }\end{array}$ & HIV+HCV & P value \\
\cline { 2 - 4 } & $\mathbf{N = 3}$ & $\mathbf{N}=\mathbf{1 4}$ & $\mathbf{N}=\mathbf{1 5}$ & \\
\hline IL-1b & 88,7 & 16,6 & 1,1 & $\mathbf{0 , 0 1}$ \\
\hline IL-2 & 280,4 & 72,7 & 15,1 & $\mathbf{0 , 0 1}$ \\
\hline FGF & 57,8 & 26,3 & 14,3 & $\mathbf{0 , 0 3}$ \\
\hline IFN-g & 1580,7 & 571,4 & 224,7 & $\mathbf{0 , 0 4}$ \\
\hline IP-10 & 70896,1 & 46985,6 & 3753,9 & $\mathbf{0 , 0 3}$ \\
\hline MIP-1a & 15862,6 & 103,0 & 20,5 & $\mathbf{0 , 0 0}$ \\
\hline MIP-1b & 14301,3 & 4732,3 & 666,5 & $\mathbf{0 , 0 1}$ \\
\hline TNF-a & 1144,8 & 155,7 & 33,7 & $\mathbf{0 , 0 1}$ \\
\hline & & & &
\end{tabular}

Authors' details

'Laboratório de Pesquisa em Infectologia, Complexo Hospitalar Prof. Edgard Santos - Federal University of Bahia, Brazil. ${ }^{2}$ FIOCRUZ, Rio de Janeiro, Brazil.

Published: 7 January 2014

doi:10.1186/1742-4690-11-S1-O8

Cite this article as: Bahia et al:: HTLV-1 infection modulates the immune response in HIV-HCV coinfected patients and may increase spontaneous HCV clearance. Retrovirology 2014 11(Suppl 1):08. 